\title{
A Reflection on the Role of Anatomists in Modern Medical Education: Confronting Meaning and Mortality in the Gross Anatomy Laboratory
}

\author{
Adam MR Groh ${ }^{1}$ \\ ${ }^{1}$ Montreal Neurological Institute and \\ Hospital, Department of Neurology and \\ Neurosurgery, McGill University

\section{Correspondence} \\ Adam M.R. Groh \\ Email: adam.groh@mail.mcgill.ca \\ Publication Date \\ January 13, 2022
}

MJM $2022(20) 18$

https://doi.org/10.26443/mjm.v20i1.940

\begin{abstract}
Modes of anatomical instruction, especially the need for trainees to dissect cadavers, have been contested for generations. The present reflection provides an opportunity to re-approach this age-old debate and contemplate the state of anatomical sciences education through a narrative reflection of a teaching assistant's encounter with a donor in the cadaveric anatomy laboratory.

\section{KEYWORDS}

Cadaveric Anatomy, Gross Anatomy, Anatomical Sciences Education, Medical Education, Medical Student
\end{abstract}

\section{McGill}

\section{Journal of Medicine}

www.mjmmed.com

\section{(c) (i) (2) (2)}

This work is licensed under a Creative Commons BY-NC-SA 4.0 International License.

My right wrist aches as I make the final touches to my chalk sketch of the abdominal wall. Swiveling in place, I see six first-year medical students filing quietly around my designated table. Their eyes are fixed far beyond my station, staring at the collection of concealed bodies arranged symmetrically on either side of the room. I cough gently, with purpose, and hazard a smile, but am immediately met with expressions of veiled apprehension. "It's okay", I tell myself; "This is their first day".
The laboratory feels poorly ventilated, almost cold. My students are staring absently at our donor while I scan the first objective on my lesson plan: "Using proper anatomical terminology, palpate the common surface landmarks on your cadaver". Realizing that our donor is still contained within her body bag, I decide to set down my list of objectives for the time being and take my group to the demonstration body - a donor that has been meticulously pre-dissected by the anatomy in- 
structors, allowing students to appreciate the relevant anatomy before tackling any intricate dissections themselves. As I unzip the body bag of this semester's demonstration body and peel back the skin overlying the abdominal wall, revealing our region of interest, I immediately hesitate because the arrangement of the skeletal muscle is so 'textbook', it feels uncanny.

Smiling politely at the eager yet tentative faces gathering around the dissection table, I carefully make my way towards the laboratory manager's office, leaving my students to inspect the relevant gross specimens surrounding the dissection table. "Do we have a cause of death for the demonstration body this semester? I'd like to know before I take my students through the abdominal wall musculature in case there are any relevant pathological abnormalities to review". Given the young age of the donor, I'm expecting to hear cardiomyopathy, brain aneurysm or perhaps glioblastoma. "Of course, just one moment", she replies faintly. "He took his own life after years of battling chronic pain".

Although I had encountered my fair share of death and suffering outside of the anatomy laboratory, something was different. To say that I understood the bewilderment of that moment would be callous and untrue, but perhaps the visceral response was to be expected. Death had to me been typically encountered within the confines of an acute, predictable event, wherein one can seek immediate support from friends and family. In these instances, we orient ourselves to tolerable levels of novelty using a set of pattern recognition mechanisms that scaffold what we know, onto what we do not. Therefore, we subconsciously deduct and reduce complexity, altering our own reality in favour of finding tranquility. Finding myself stuck in this incongruous laboratory environment without any support or prior frame of reference, I had no idea how to reconcile the tragedy of the moment with the need to instruct my students in a calculated manner. The sudden juxtaposition of the affective nature of an academic discipline that relies on the precise scrutiny of human flesh, with the need to remain assertive and reassuring as an instructor, was jarring. It was only in this very moment, after years of precise dissection and meticulous anatomical study, that I realized I was not trained for this.

My gut reaction when confronted with such an existential pressure was to test the strength of our collective resolve. I felt that to share in the tragedy and strange beauty of the moment would create a learning opportunity like no other. These students would have to deal with the stark reality of death almost every day as clinicians, would they not? Surely confessing this truth was not beyond the bounds of the difficulties one might expect to face when entering the cadaveric anatomy laboratory. But on the other hand, who was I to guide these students through a transition that may very well define their budding medical careers? A knowledgeable anatomist, armed with hundreds of clinical cases and targeted dissection techniques, is left largely adrift and unmoored when confronted with the most blatant of human truths. And so, with the weight of the moment slowly suffocating me to the point of compelled action, I quietly explained to my students how our donor came to arrive in the laboratory.

The immense sense of privilege I felt in that moment will stay with me for the rest of my life, and I hope so, too, with my students. The selfless act of body donation establishes a seldom stated yet fundamentally important contract between those who once were, and those who are yet to be. When presented with an inexperienced and faceless explorer, the donor (patient) demonstrates complete trust, even in their most vulnerable state. The young medical student is gifted the opportunity to freely explore the body of a voiceless companion far before they are an accredited healthcare professional. And it is here, in a student's moment of fear and unease, that their instructor may, and perhaps should, choose to imbue a sense of humanity to an otherwise rigid empirical science, denoting the importance of a ritual in medicine which transcends boundaries of life and death.

An anatomist spends thousands of hours dissecting diverse donors and engaging in a variety of specialized coursework to develop the competency needed to teach (1). It is paramount for the medical student that 
their instructor can field questions concerning intricate structural relationships or curious pathological abnormalities. And yet, these same instructors typically spend limited to no hours preparing to teach their students about death and the difficulties of learning in a cadaveric anatomy laboratory (2). Modernization of education in the anatomical sciences has provided an enormous number of learning resources from virtual reality laboratories to 3D phone applications $(3,4)$. Complex anatomy can now theoretically (and soon, I dare say, in practice) be mastered from the convenience of one's living room. In this context, the need for formally trained anatomists in medical education may be dwindling.

Reflecting on this age-old pedagogical dichotomy, where anatomy can be conceptualized as both an immutable science and an iterative study of what it means to be human, we must ask ourselves: is it a disservice to the donor (patient) if this unique environment is not explicitly utilized to help the budding physician develop a sense of moral responsibility? And further, does the anatomist have the training necessary to mediate this nascent patient-physician relationship? Unless we bolster a curriculum that attempts to grasp the ineffable, human side of anatomy, it may be the case that formal cadaveric dissection courses continue to disappear across the country (5). An inter-disciplinary approach to teaching anatomy that is inclusive of disciplines outside of the traditional medical sciences (such as philosophy, anthropology, or sociology) may be a key component in modern medical curricula that strive to maintain gross anatomy laboratories and necessitate the training of anatomists for future generations.

\section{ACKNOWLEDGEMENTS}

The author would like to sincerely thank all individuals who provided input into this reflection. For the sake of confidentiality due to the subject matter of the piece, their names have not been listed. Lastly, the author would like to express their immense gratitude to the selfless donors who have made such research, education and reflection a possibility.
Addendum: This article was written based on an academic experience that did not occur at McGill University. The descriptions provided in this piece do not reflect the current protocols or opinions of McGill University, its faculties, or departments. Please see our Policy on Published Editorial Materials for more information.

\section{REFERENCES}

1. Schaefer AF, Wilson AB, Barger JB, Azim HM, Brokaw JJ, Brooks WS. What does a modern anatomist look like? Current trends in the training of anatomy educators. Anatomical sciences education. 2019 May;12(3):225-35.

2. Evans DJ, Pawlina W. The role of the anatomist in teaching of nontraditional discipline-independent skills. In Teaching Anatomy 2020 (pp. 459-471). Springer, Cham.

3. Wilson AB, Miller CH, Klein BA, Taylor MA, Goodwin M, Boyle EK, Brown K, Hoppe C, Lazarus M. A meta-analysis of anatomy laboratory pedagogies. Clinical Anatomy. 2018 Jan;31(1):122-33.

4. Iwanaga J, Loukas M, Dumont AS, Tubbs RS. A review of anatomy education during and after the COVID-19 pandemic: Revisiting traditional and modern methods to achieve future innovation. Clinical Anatomy. 2021 Jan;34(1):108-14.

5. Rockarts J, Brewer-Deluce D, Shali A, Mohialdin V, Wainman B. National survey on Canadian undergraduate medical programs: The decline of the anatomical sciences in Canadian medical education. Anatomical sciences education. 2020 May;13(3):381-9. 